\title{
Use of Numerical Groundwater Modeling to Evaluate Uncertainty in Conceptual Models of Recharge and Hydrostratigraphy
}

\author{
Karl Pohlmann ${ }^{1}$ (702-862-5485; Karl.Pohlmann@dri.edu) \\ Ming Ye ${ }^{2}$ (MingYe@scs.fsu.edu) \\ Greg Pohll ${ }^{3}$ (Greg.Pohll@dri.edu) \\ Jenny Chapman ${ }^{1}$ (Jenny.Chapman@dri.edu $)$ \\ ${ }^{1}$ Desert Research Institute, Nevada System of Higher Education, 755 East Flamingo Road, Las \\ Vegas, NV 89119 \\ ${ }^{2}$ School of Computational Sciences and Department of Geological Sciences, Florida State \\ University, Tallahassee, FL 32306 \\ ${ }^{3}$ Desert Research Institute, Nevada System of Higher Education, 2215 Raggio Parkway, Reno, \\ NV 89512
}

Numerical groundwater models are based on conceptualizations of hydrogeologic systems that are by necessity developed from limited information and therefore are simplifications of real conditions. Each aspect (e.g. recharge, hydrostratigraphy, boundary conditions) of the groundwater model is often based on a single conceptual model that is considered to be the best representation given the available data. However, the very nature of their construction means that each conceptual model is inherently uncertain and the available information may be insufficient to refute plausible alternatives, thereby raising the possibility that the flow model is underestimating overall uncertainty. In this study we use the Death Valley Regional Flow System model developed by the U.S. Geological Survey as a framework to predict regional groundwater flow southward into Yucca Flat on the Nevada Test Site. An important aspect of our work is to evaluate the uncertainty associated with multiple conceptual models of groundwater recharge and subsurface hydrostratigraphy and quantify the impacts of this uncertainty on model predictions. In our study, conceptual model uncertainty arises from two sources: (1) alternative interpretations of the hydrostratigraphy in the northern portion of Yucca Flat where, owing to sparse data, the hydrogeologic system can be conceptualized in different ways, and (2) uncertainty in groundwater recharge in the region as evidenced by the existence of several independent approaches for estimating this aspect of the hydrologic system. The composite prediction of groundwater flow is derived from the regional model that formally incorporates the uncertainty in these alternative input models using the maximum likelihood Bayesian model averaging method. An assessment of the joint predictive uncertainty of the input conceptual models is also produced. During this process, predictions of the alternative models are weighted by model probability, which is the degree of belief that a model is more plausible given available prior information (expert opinion) and site measurements (hydraulic head and groundwater flux). The results indicate that flow simulations in Yucca Flat are more sensitive to hydrostratigraphic model than recharge model. Furthermore, posterior model uncertainty is dominated by inter-model variance as opposed to intra-model variance, indicating that conceptual model uncertainty has greater impact on the results than parametric uncertainty. Without consideration of conceptual model uncertainty, uncertainty in the flow predictions would be significantly underestimated. Incorporation of the uncertainty in multiple conceptual models renders the groundwater flow model predictions more scientifically defensible. 